Classification

Physics Abstracts

$6140 \mathrm{~K}-6116 \mathrm{P}-6820$

\title{
SEM, ToF-SIMS and LFM morphological study of an heterogeneous polymeric surface
}

\author{
Bernard Nysten $\left({ }^{1}\right)$, Geert Verfaillie $\left({ }^{1}\right)$, Etienne Ferain $\left({ }^{1}\right)$, Roger Legras $\left({ }^{1}\right)$, Jean-Benoit \\ Lhoest $\left({ }^{2}\right)$, Claude Poleunis $\left({ }^{2}\right)$ and Patrick Bertrand $\left({ }^{2}\right)$ \\ ( $\left.{ }^{1}\right)$ Unité de Chimie et de Physique des hauts Polymères, Université catholique de Louvain, place \\ Croix du Sud, 1, B-1348 Louvain-la-Neuve, Belgium \\ ${ }^{2}$ ) Unité de Physico-Chimie et de Physique des Matériaux, Université catholique de Louvain, place \\ Croix du Sud, 1, B-1348 Louvain-la-Neuve, Belgium
}

(Received July 4; accepted October 26, 1994)

\begin{abstract}
Résumé. - Des films présentant une surface hétérogène ont été obtenus par moulage sous pression de mélanges de deux polymères incompatibles : le polypropylène $(\mathrm{PP})$ et le polyéthylène téréphtalate (PET). La morphologie de surface de films obtenus à partir de $20 \%$ de PP et $80 \%$ de PET à été étudiée par microscopie électronique à balayage (SEM), spectrométrie de masse d'ions secondaires (ToF-SIMS) et microscopie de force latérale. Les trois méthodes ont révélé une surface hétérogène constituée de nodules dont le diamètre varie entre 1 et $100 \mu \mathrm{m}$ dispersés dans une phase continue. Les analyses en ToF-SIMS ont permis l'identification de la nature chimique de cette hétérogénéité : la phase continue est constituée de PET et les nodules de PP. Les études en SEM et en LFM ont également révélé les nodules en surface. Cette étude a mis en évidence la complémentarité des trois méthodes utilisée pour l'étude de la morphologie de surface des alliages de polymère.
\end{abstract}

\begin{abstract}
Films with an heterogeneous surface have been obtained by compression moulding of mixtures of two incompatible polymers: poly(propylene) (PP) and poly(ethylene terephtalate) (PET). The surface morphology of films prepared with $20 \%$ of PP and $80 \%$ of PET has been studied by means of various methods: scanning electron microscopy (SEM), time of flight secondary ion mass spectrometry (ToF-SIMS) and lateral force microscopy (LFM). The three methods revealed an heterogeneous surface with a cor ${ }^{+}$inuous phase including nodules whose size ranges from approximately $1 \mu \mathrm{m}$ to more than $100 \mu \mathrm{m}$. 'ob-SIMS analyses identified the chemical nature of this heterogeneity: the continuous phase is PET and the nodules are PP. SEM and LFM were also found to be able to image the surface nodules. This study proved the complementarity of the three methods for the characterisation of the surface morphology of polymer blends.
\end{abstract}

Polymer blending actually forms an important field in polymer research because the mixture of different polymers offers the possibility of creating new materials with synergetic properties. Blending is in fact more time and cost effective for the creation of new materials than the chemical synthesis of new polymers.

Since most polymers are immiscible at molecular scale, a two phase system generally results from the mixture of two polymers. The blend properties depend on its morphology. This mor- 
phology is influenced by a lot of parameters such as mixing time, shear rate, viscosity, elasticity, reactivity,... Many strategies have been developed to control these parameters in order to obtain the desired bulk morphology and thus the desired properties [1-6].

However, if bulk morphology can be now controlled, it is still not the case for the surface morphology. Though there is much work done on solvent-cast copolymers and polymer blends, there is in fact little work performed to study the parameters linking the bulk and the surface morphologies of immiscible polymer blends after melt processing [7]. However the control of the surface heterogeneity in order to tailor for example the adhesive properties of blends or their biocompatibility is of main interest. The present study aims to create a polymeric biomaterial presenting an heterogeneous surface with regions of different hydrophilicity. The objective is to create heterogeneity sizes ranging from $0.1 \mu \mathrm{m}$ to $500 \mu \mathrm{m}$ (i.e. from the sub-cellular scale to the supra-cellular scale) in order to measure the biological response to these surface heterogeneities.

In the present case, the surface heterogeneity was obtained through the mixing of two incompatible polymers: a more hydrophilic polymer, poly(ethylene terephtalate) (PET) and a more hydrophobic one, poly(propylene) (PP). The polymer blend was prepared using a Brabender plastograph at $280^{\circ} \mathrm{C}$ and $50 \mathrm{rpm}$ under nitrogen atmosphere. Films were then compression moulded between two Kapton surfaces at $280^{\circ} \mathrm{C}$ under a pressure of $\approx 1.4 \mathrm{MPa}$. The complete procedure used to obtain these films will be described in details elsewhere [8].

In the present study, films made of $20 \%$ of PP and $80 \%$ of PET were analysed. Their surface morphology was characterised by means of three different techniques: scanning electron microscopy (SEM), time of flight secondary ion mass spectrometry (ToF-SIMS) and lateral force microscopy (LFM). A previous study has already shown that SEM and ToF-SIMS imaging can be used to characterise the surface morphology of PVC/PMMA blends [9].

SEM images were obtained on a Hitachi 5570 microscope. The sample surface was coated with an approximately $10 \mathrm{~nm}$ thick film of $\mathrm{Au} / \mathrm{Pd}$ and the voltage acceleration was equal to $15 \mathrm{kV}$.

ToF-SIMS spectra and images were obtained with a Charles Evans Time of Flight SIMS spectrometer $[10,11]$. A pulsed ${ }^{69} \mathrm{Ga}^{+}$ion beam $(15 \mathrm{keV}$ for a spectrum acquisition or $25 \mathrm{keV}$ for an image acquisition) was focused (600 nm diameter) and rastered over sample surface. The operating conditions in image acquisition were the following: 400 pA DC current, 20 nsec pulse width and $5 \mathrm{kHz}$ repetition rate. For spectrum acquisition, the ion pulse was further bunched up to $1.5 \mathrm{nsec}$ before reaching the sample. The ion dose was kept below $10^{12}$ ions $\mathrm{cm}^{-2}$ to insure static conditions (i.e. to keep information coming from unperturbated surface regions) [12]. The secondary ions emitted by the surface were extracted and mass analysed by time of flight technique. The charge compensation was achieved by means of a grounded non magnetic stainless steel grid covering the sample and by a pulsed electron beam $(24 \mathrm{eV})$.

Contact AFM and LFM images were obtained using an Autoprobe CP from Park Scientific Instruments (Sunnyvale, CA). On this system a four quadrants photodiode enables the simultaneous recording of the lever deflection due to the surface topography and of the lever torsion attributed to the lateral friction forces acting on the tip. Pyramidal silicon nitride tips mounted on microlevers with a force constant equal to $0.5 \mathrm{~N} \mathrm{~m}^{-1}$ where used for these observations. Typical scan speeds ranged between 10 and $20 \mu \mathrm{m} \mathrm{sec}^{-1}$ and typical contact forces ranged between 50 and $150 \mathrm{nN}$.

The first observations by SEM revealed an heterogeneous surface consisting in nodules with diameters ranging from 1 to $100 \mu \mathrm{m}$ dispersed in a continuous matrix (Fig. 1). The matrix was naturally identified as being PET and the nodules as PP. However, since secondary electrons responsible for the SEM images are emitted not only from the surface but also from the bulk (depth $\approx 50 \mathrm{~nm}$ ) [13], it was not clear whether the PP nodules are actually present at the outermost film surface or not. Therefore, ToF-SIMS and LFM analyses which are more sensitive to the outermost surface were performed to check that the heterogeneity observed by SEM is really present at the 


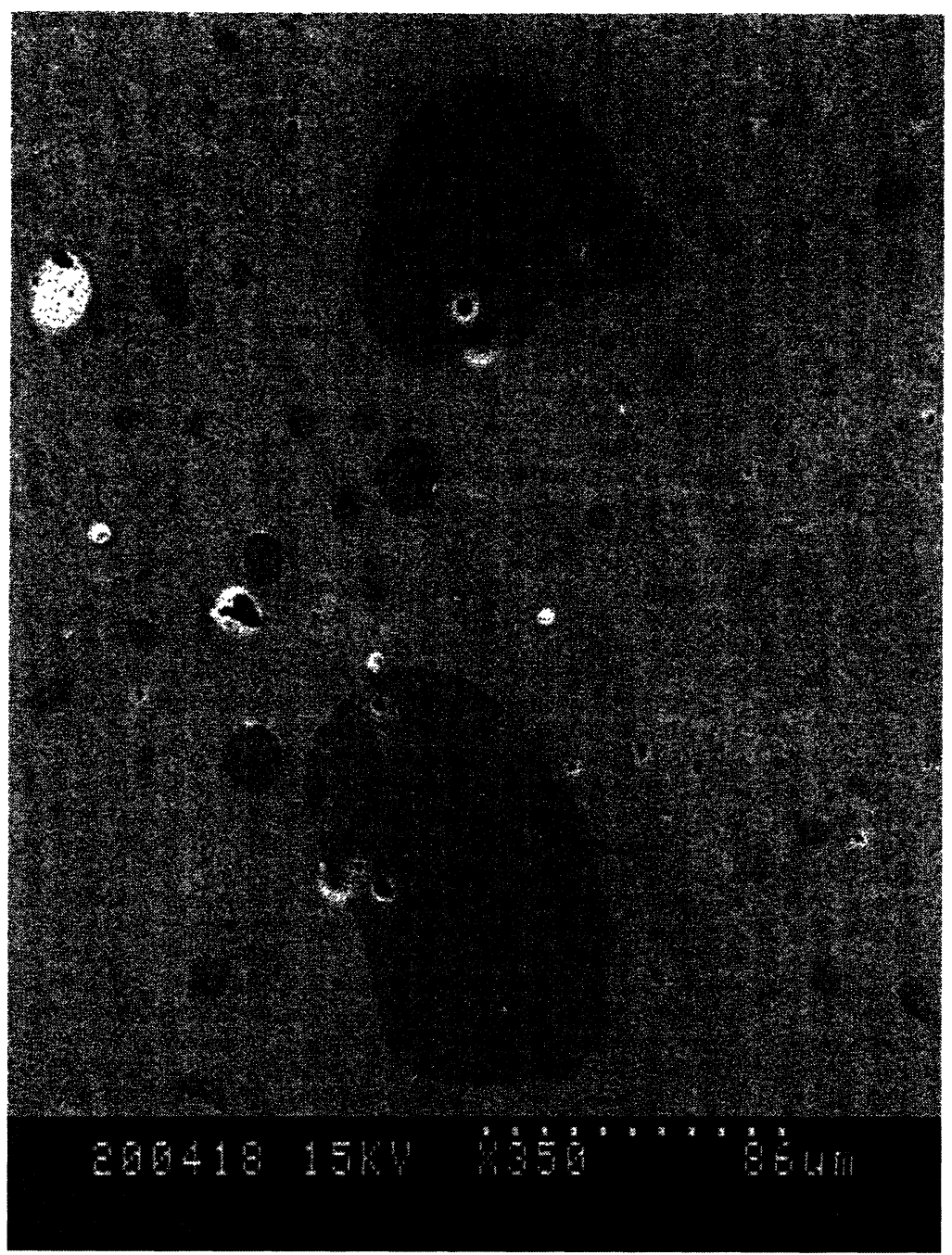

Fig. 1. - SEM image of the surface of the PP/PET 20/80 film also observed with the two other techniques. Darker regions are attributed to PP nodules.

film surface. Especially the same region of a film was observed by means of the three techniques in order to check that they give the same informations.

ToF-SIMS studies first showed that the film surface is almost free from significant inorganic contamination. On one hand, positive- and negative-ToF-SIMS spectra are typical for PET (Fig. 2). The interpretation of the spectra is given in [14]. On the other hand, ToF-SIMS images recorded with $\mathrm{C}_{6} \mathrm{H}_{4}^{+}, \mathrm{C}_{7} \mathrm{OH}_{4}^{+}$and $\mathrm{C}_{8} \mathrm{O}_{3} \mathrm{H}_{5}^{+}$ions and with $\mathrm{O}^{-}$and $\mathrm{OH}^{-}$ions which are characteristic of the $\mathrm{PET}$ phase revealed an heterogeneous surface with nodules from which no selected ions are detected (Fig. 3a,b). Both observations confirmed that the continuous phase is constituted of PET and that the PP nodules are present at the outermost surface of the films. Indeed, in static conditions, the analysed molecular ions are coming from the first monolayer. $\mathrm{C}^{-}$and $\mathrm{CH}^{-}$ions image of the same region as that analysed by SEM did not reveal any surface topography (Fig. 

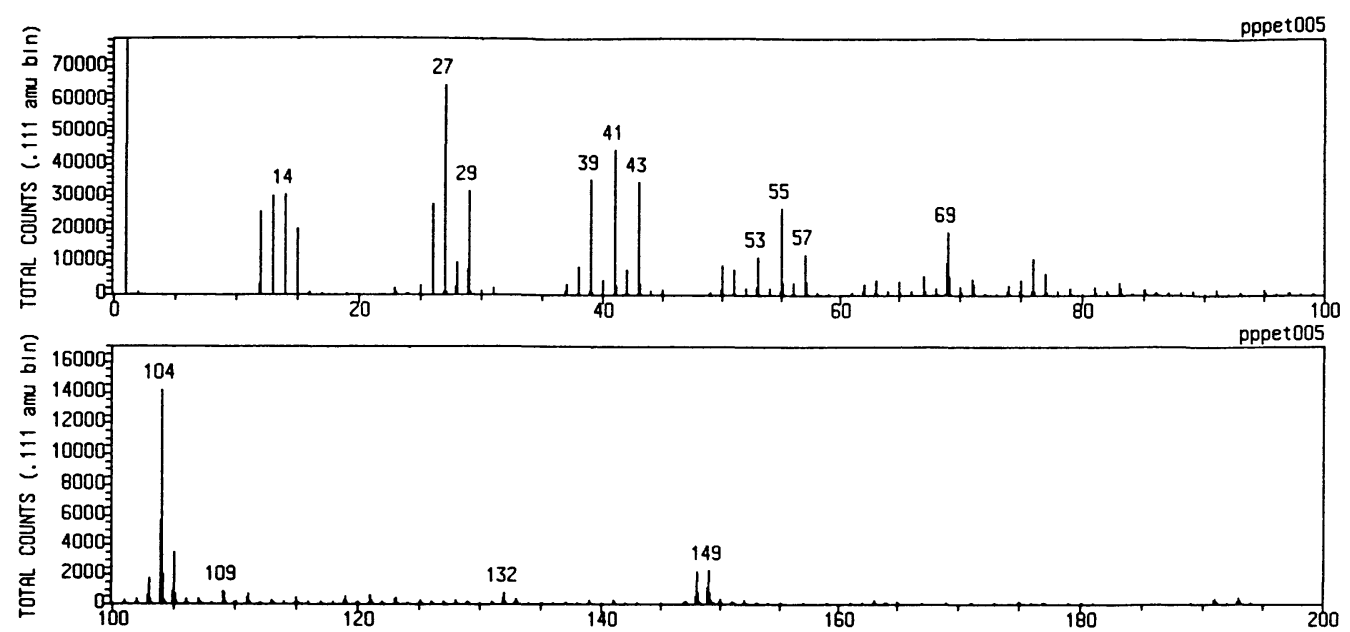

(a)
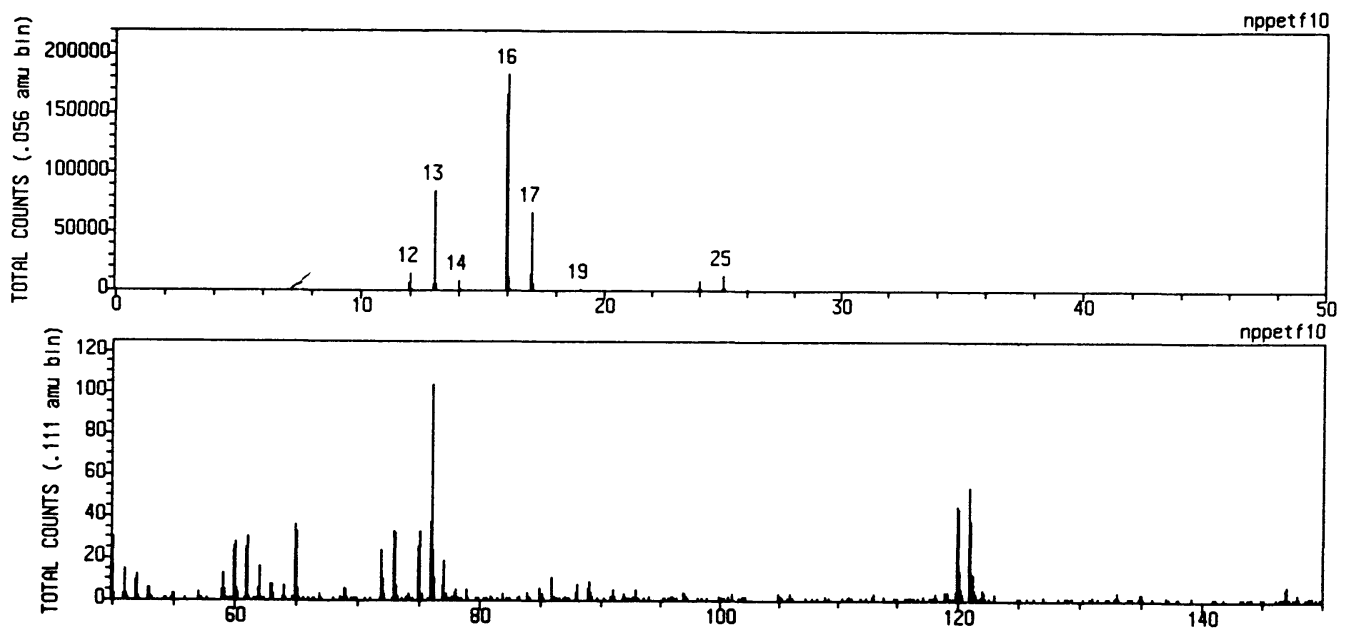

(b)

Fig. 2. - a) ToF-SIMS positive ions spectrum of the surface of the PP/PET film. b) Negative ions spectrum of the same surface.

3c) while $\mathrm{O}^{-}$ions image of this region revealed the same morphology as that observed by SEM (Fig. 3d).

LFM also revealed the same surface heterogeneity as that visualised by ToF-SIMS (Fig. 4). Various reasons could account for the contrast observed in this case: i) a surface topography associated with the PP nodules, ii) a difference in the surface roughness on the matrix and on the nodules or iii) a difference in the physico-chemical properties of both polymers.

However, the two first explanations could be rejected. On the one hand, as it can be seen in figure $4 \mathrm{c}$, d, some nodules appear on the LFM image while they do not appear on the topographic image. The weak surface corrugation $(<0.1 \mu \mathrm{m})$ observed between the matrix and the nodules (Fig. 4c) also confirms that the contrast observed in the ToF-SIMS images could not be attributed to surface topography. On the other hand, roughness analyses performed on regions of the matrix 

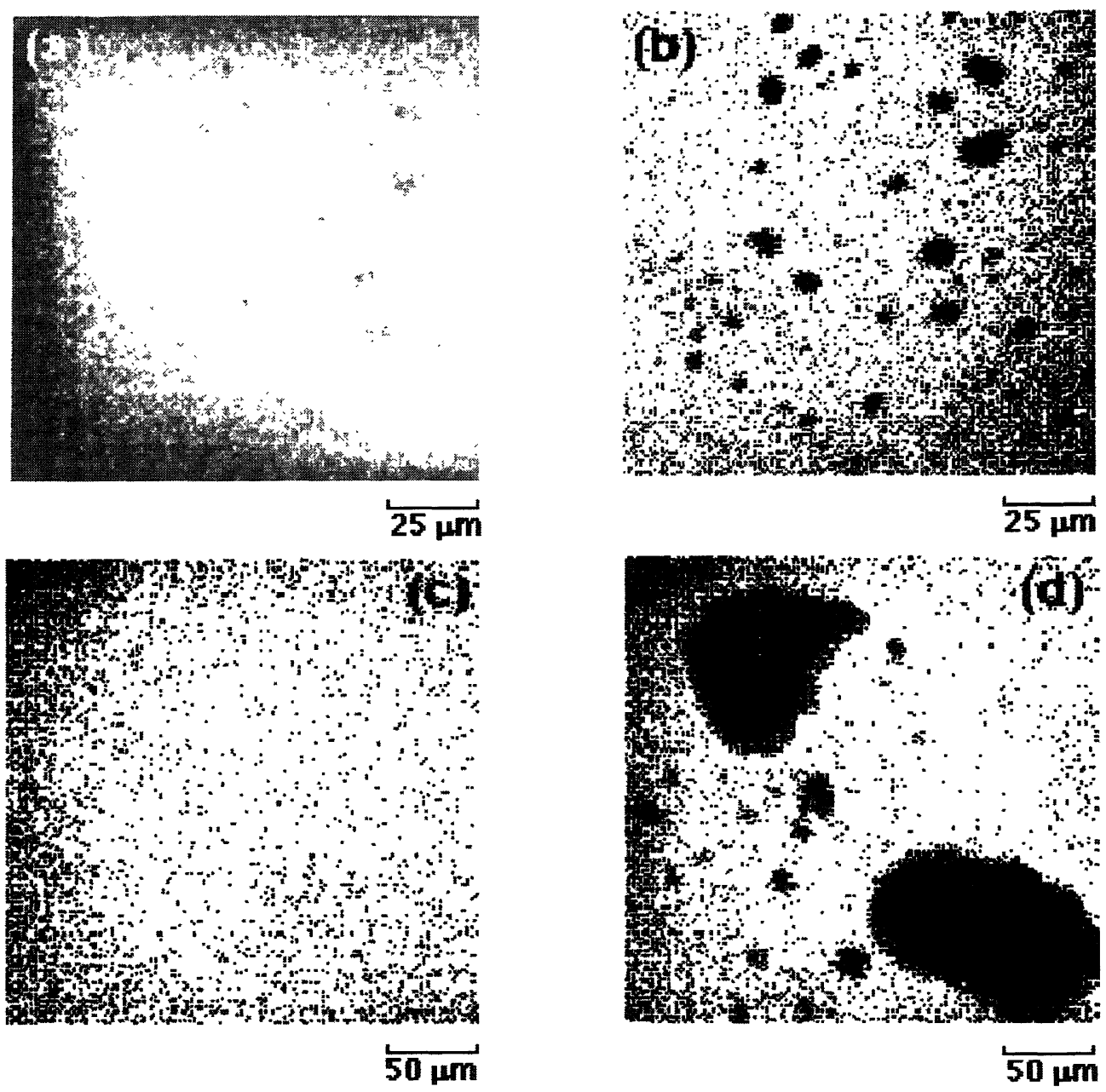

Fig. 3. - a) $\mathrm{C}_{6} \mathrm{H}_{4}^{+}, \mathrm{C}_{7} \mathrm{OH}_{4}^{+}$and $\mathrm{C}_{8} \mathrm{O}_{3} \mathrm{H}_{5}^{+}$ions ToF-SIMS image of the surface of the PP/PET film. b) $\mathrm{O}^{-}$and $\mathrm{OH}^{-}$ions ToF-SIMS image of the same region as in (a). The color scale reflects the intensity of detected ions characteristic of PET at each point of the images. Darker regions correspond to regions where no selected ions are detected, i.e. PP nodules, and brighter regions correspond to PET. c) $\mathrm{C}^{-}$and $\mathrm{CH}^{-}$ions image of the region of the film analysed with the two other techniques. d) $\mathrm{O}^{-}$ions ToF-SIMS image of the same region as in c).

surface and on the nodules surface revealed that the RMS roughness $\left({ }^{1}\right)$ is the same on the PET phase and the PP phase ( $<5 \mathrm{~nm}$ at the $\mu$ m surface scale).

Obviously, the contrast in LFM is directly associated with the difference in the nature and/or the physico-chemical properties of the polymers present at the matrix and the nodule surfaces. The most probable property which could be responsible for the difference of friction force is the

$\left({ }^{1}\right)$ The RMS roughness of a region is defined as $\sqrt{\sum_{i=1}^{N}\left(z_{i}-\bar{z}\right)^{2} /(N-1)}$ where $z_{i}$ is height of a point and $\bar{z}$ is the mean height of the region. The summation is performed on all the $N$ points (pixels) of the analysed region. 


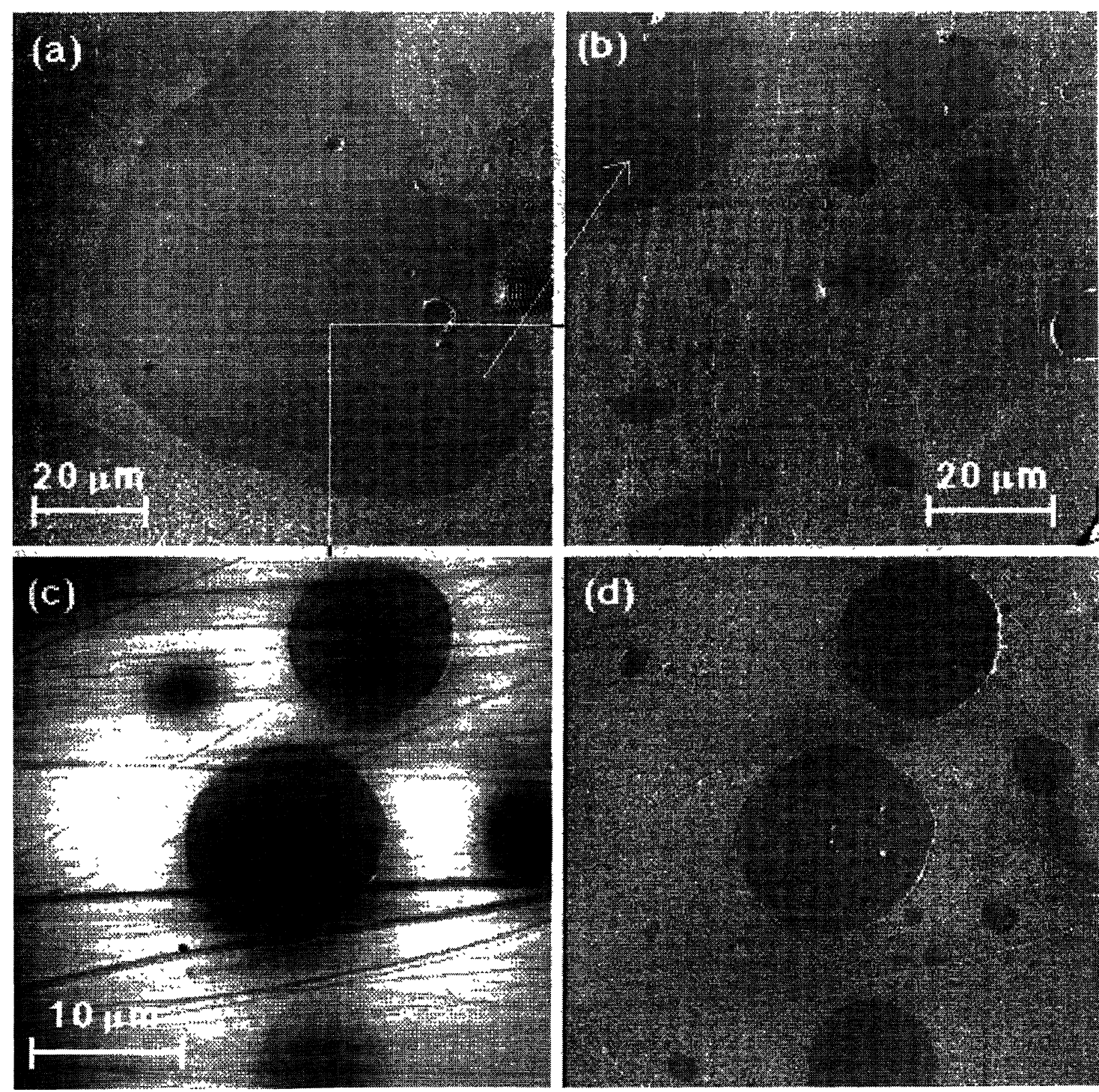

Fig. 4. - a), b) LFM images of the same region observed by SEM and ToF-SIMS. The color scale reflects the intensity of the torsion of the lever. Brighter regions correspond to zones where the lateral force is stronger. c) Topographic AFM image of a PP/PET film. The color scale corresponds to a surface corrugation of 0.10 $\mu \mathrm{m}$. d) LFM image of the same region as in c). Some PP nodules not revealed on the topographic image are revealed by this LFM image.

difference in hydrophilicity of both polymers as determined by the difference in Zisman's critical tension for wetting (Tab. I) [15]. The higher surface polarity of PET could thus induce a higher friction force. Another reason which could explain the contrast in LFM is the fact that the shear modulus of PET is about twice that of PP [16]. This would induce a higher friction force on the PET surface than on the PP surface. Indeed, it has been previously shown that the friction force is higher on fluorinated Langmuir-Blodgett films than on their hydrogen-containing counterpart because the shear resistance of the fluorinated films is higher [17]. These results shows that lat- 
Table I. - Zisman's critical tension for wetting $\left(\gamma_{\mathrm{c}}\right)$ for PP and PET [15].

\begin{tabular}{cc}
\hline \hline Polymer & $\gamma_{c}\left[\mathrm{~mJ} \mathrm{~m}^{-2}\right]$ \\
\hline PP & 29 \\
PET & 43 \\
\hline \hline
\end{tabular}

eral force microscopy could be used to reveal chemical heterogeneities at the surface of polymer blends.

Comparison of images in figure 1 , figure $3 \mathrm{c}$ and figure $4 \mathrm{a}$, b clearly shows that the three techniques reveal the same surface morphology. The present study proved the complementarity of the three methods of surface analysis, each method having its own advantages.

ToF-SIMS images are sensitive to the outermost surface of the sample and give a direct chemical information on the surface composition. It thus enables to check the chemical nature of the surface heterogeneity observed by means of the other techniques. It however necessitates the use of ultra-high vacuum techniques and its lateral resolution under our experimental conditions is limited to $0.5 \mu \mathrm{m}$ on polymers.

SEM present the advantage to enable the rapid acquisition of a large number of images in order to perform a statistical analysis of the surface heterogeneity. Its lateral resolution is better than in ToF-SIMS (a few tens of nanometers) [13]. However, it necessitates the use of other surface techniques to check that the observed nodules are actually present at the outermost surface. It also necessitates a coating of the samples which prevent further analyses on the same samples.

Finally LFM observations present the advantage like ToF-SIMS to probe the outermost surface of the samples. It also does not necessitate any special preparation of the samples and enables their observation under ambient conditions. It has a lateral resolution which could theoretically go down to the atomic scale. However, for technological reasons related to tip fabrication, it is presently limited like in SEM to a few tens of nanometers.

\section{Acknowledgements.}

This work is supported by the "Biomaterials" program of the Région Wallonne of Belgium. The ToF-SIMS and the AFM equipments were acquired thanks to the support of the FRFC of Belgium.

\section{References}

[1] Favis B.D., J. Appl. Polym. Sci. 39 (1990) 285.

[2] Favis B.D. and Chalifoux J.P., Polymer 29 (1988) 1791.

[3] Favis B.D. and Willis J.M., J. Polym. Sci. 28 (1990) 2259.

[4] Wu S., Polym. Eng. Sci. 27 (1987) 335.

[5] Serpe G., Jarrin J. and Dawans F., Polym. Eng. Sci. 30 (1990) 553. 
[6] Xanthos M., Polym. Eng. Sci. 28 (1988) 1392.

[7] Bhatia Q.S., Burrell M.C. and Chera J.J., J. Appl. Polym. Sci. 46 (1992) 1915.

[8] Verfaillie G., Ferain E. and Legras R., to be published.

[9] Jackson S.T. and Short R.D., J. Mater. Chem. 2 (1992) 259.

[10] Schueler B., Sander P. and Reed D.A., Vacuum 41 (1990) 1661.

[11] Schueler B., Microsc. Microanal. Microstruct. 3 (1992) 119.

[12] Marletta G., Catalano S.M. and Pignataro S., Surf. Interf. Analys. 16 (1990) 407.

[13] Sawyer L.C. and Grubb D.T., Polymer Microscopy (Chapman and Hall, London, 1987) 24.

[14] Briggs D., Brown A. and Vickerman J.C., Handbook of Static Secondary Ion Mass Spectrometry (SIMS) (John Wiley \& Sons, Chichester, 1989).

[15] Lee L.H., Fundamentals of Adhesion (Plenum Press, New York, 1990) 53-57.

[16] Mark H.F., Bikales N.M., Overberger C.G. and Menges G., Encyclopedia of Polymer Science and Engineering (John Wiley \& Sons, New York, 1988).

[17] Overnay R., Meyer E., Frommer G., Brodbeck D., Lüthi R., Howard L., Güntherodt H.-J., Fujihira M., Takano H. and Gotoh Y., Nature 359 (1992) 349. 